\title{
Transcatheter aortic valve implantation results are not superimposable to surgery in patients with aortic stenosis at low surgical risk
}

\author{
Maria Cristina Acconcia ${ }^{1}$, Marco Alfonso Perrone ${ }^{2}$, , Domenico Sergi $^{2}$, \\ Marco Di Luozzo ${ }^{2}$, Massimo Marchei ${ }^{2}$, Pasquale De Vico ${ }^{2}$, Antonio Sili Scavalli ${ }^{1}$, \\ Giuseppe Pannarale ${ }^{1}$, Marcello Chiocchi ${ }^{3}$, Carlo Gaudio ${ }^{1}$, Francesco Romeo ${ }^{2}$, \\ Quintilio Caretta ${ }^{4 *}$, Francesco Barillà ${ }^{1 *}$ \\ ${ }^{1}$ Department of Cardiovascular Disease, University of Rome La Sapienza, Rome, Italy \\ ${ }^{2}$ Department of Cardiovascular Disease, University of Rome Tor Vergata, Rome, Italy \\ ${ }^{3}$ Department of Diagnostic Imaging, Molecular Imaging, Interventional Radiology and Radiotherapy, \\ University of Rome Tor Vergata, Rome, Italy \\ ${ }^{4}$ Department of Experimental and Clinical Medicine, University of Florence, Italy
}

\begin{abstract}
Background: The aim of this meta-analysis was to compare the impact of transcatheter aortic valve implantation (TAVI) vs. surgical aortic valve replacement (SAVR) in patients with severe aortic valve stenosis (AS) at low surgical risk.

Methods: All randomized controlled trials (RCTs) and observational studies (Obs) published from January 2014 until March 31', 2020 were retrieved through the PubMed computerized database and at the site https://www.clinicaltrials.com. The relative risk (RR) with the 95\% confidence interval (CI) was used to evaluate the effect of the intervention under comparison. The primary endpoints were all-cause 30-day mortality and 1-year mortality. The 30-day safety endpoints were: stroke, acute kidney injury stage 2 or 3, major bleeding, moderate/severe paravalvular leak, need for new permanent pacemaker (PM) implantation. Results: After detailed review 9 studies, related to 4 RCTs and 5 Obs, were selected. The overall analysis of RCTs plus Obs showed a significantly lower 30-day mortality for TAVI $(R R=0.55 ; 95 \% C I$ $\left.0.45-0.68, p<0.00001 ; I^{2}=0 \%\right)$. However, an increased risk of new PM implantation (RR = 2.87; 95\% CI 2.01-3.67, $\left.p<0.00001, I^{2}=0 \%\right)$ and of paravalvular leak $(R R=7.28 ; 95 \%$ CI 3.83-13.81, $p<0.00001, I^{2}=0 \%$ ) was observed in TAVI compared to SAVR. On the contrary, a lower incidence of major bleeding $\left(R R=0.38 ; 95 \%\right.$ CI 0.27-0.54, $\left.p<0.00001, I^{2}=0 \%\right)$ and of acute kidney injury was observed ( $R R=0.33 ; 95 \%$ CI 0.19-0.56, $p<0.0001, I^{2}=0 \%$ ) in TAVI.

Conclusions: TAVI and SVAR in the treatment of AS in the patients at low surgical risk are not superimposable. In particular, if 30-day and 1-year mortality, major bleeding and acute kidney injury were significantly lower for TAVI, the need of new PM implantation and paravalvular leak were significantly lower in SAVR. Consequently, we suggest the need of more trials to evaluate the effectiveness of TAVI as routine therapeutic procedure in the treatment of patients with low surgical risk AS. (Cardiol J)

Key words: transcatheter aortic valve interventions, transcatheter aortic valve implantation, aortic stenosis, prosthetic aortic valves, low surgical risk, meta-analysis
\end{abstract}

Address for correspondence: Marco Alfonso Perrone, MD, Department of Cardiovascular Disease, University of Rome Tor Vergata, Via Montpellier, 1 - 00133 Rome, Italy, tel: +39-0620904009, fax: +39-0620904008,

e-mail: marco.perrone@uniroma2.it

Received: 11.07.2020 Accepted: 8.02.2021 Early publication date: 30.09.2021

*Equal contribution

This article is available in open access under Creative Common Attribution-Non-Commercial-No Derivatives 4.0 International (CC BY-NC-ND 4.0) license, allowing to download articles and share them with others as long as they credit the authors and the publisher, but without permission to change them in any way or use them commercially. 


\section{Introduction}

Surgical aortic valve replacement (SAVR) had been the only effective therapy for patients with aortic stenosis (AS) until the introduction into clinical practice of transcatheter aortic valve implantation (TAVI). The remarkable advances in bioengineering technology and interventional cardiology techniques over the years have benefited from the following issues: (i) a drastic reduction in mortality rates, (ii) a significant reduction of complications, due to better patient selection and preprocedural computerized tomography, and (iii) greater operator experience. The robust evidence in favor of TAVI resulting from randomized controlled trials (RCTs) were summarized in the international guidelines $[1,2]$ that strongly recommend TAVI in inoperable, high- or intermediate-risk patients. Recently, on the basis of RCTs and registries, TAVI was successfully reported in patients with intermediate and low surgical risk with comparable or even better results than SAVR [3-14]. Moreover in 2019, PARTNER 3 and EVOLUT LOW RISK trials, performed on patients with severe AS at low risk of death with surgery, demonstrated benefits of TAVI over surgery $[9,11]$. As a consequence, recently the United States Food and Drug Administration (FDA) first approved an expanded indications for several transcatheter heart valves (the Edwards Lifesciences's Sapien 3 and Sapien 3 Ultra, and self-expanding Medtronic CoreValve Evolut R and CoreValve Evolut PRO) including patients who are at low surgical risk for death or major complications associated with open-heart surgery (https:// www.fda.gov/news-events/press-announcements/ fda-expands-indication-several-transcatheterheart-valves-patients-low-risk-death-or-major. Accessed May 14, 2020). Indeed, on the basis of the results of PARTNER 3 trial, Edwards Lifesciences announced that SAPIEN 3 valve cleared for use in low-risk patients in Europe (https://www.edwards. com/ns20191106. Accessed May 14, 2020). As encouraging data continue to emerge, TAVI seems destined to replace SAVR as the gold standard therapy of AS $[15,16]$.

Based on the previous evidence, the aim of our meta-analysis of RCTs and observational studies (Obs) was to compare TAVI vs. SAVR in patients with AS at low surgical risk.

\section{Methods}

The present meta-analysis was performed in accordance with the Preferred Reporting Items for
Systematic Reviews and Meta-Analyses (PRISMA) statement. The literature search was performed through PubMed and Cochrane computerized database and at the site https://clinicaltrials.gov, in order to include all studies published between January 2014 to March $31^{\text {st }}, 2020$ reporting on TAVI vs. trans-vascular SAVR in patients with severe AS at low surgical risk. The low-risk population was defined by STS score $<4 \%$ (Society of Thoracic Surgeons Predicted Risk of Mortality [STS-PROM]) or Logistic (European System of Cardiac Operative Risk Evaluation [LES]) Euroscore $<10 \%$ ) [17-19]. The reference lists of retrieved full-text articles were also examined to identify potentially relevant studies not selected by the electronic search.

Two investigators independently performed the studies selection with the aim to include only studies that reported 30-day and/or at least one of the safety endpoints under evaluation. Conflicts were resolved by consulting a third investigator.

Studies published in languages other than English, conference abstracts or proceedings, TAVI performed using transapical approach, SAVR performed with sutureless prostheses and duplicate studies, were excluded from the meta-analysis.

\section{Outcomes}

The primary endpoints were all-cause 30-day mortality and 1-year mortality. The 30-day safety endpoints were: the need for new permanent pacemaker (PM) implantation, major bleeding (including major, life threatening, or disabling bleeding), acute kidney injury stage 2 or 3 , stroke, moderate/ /severe paravalvular leak. Endpoint criteria were selected according to the standardized definitions of the Valve Academic Research Consortium (VARC)-2 [20].

\section{Statistical analysis}

The meta-analysis was performed using Review Manager (RevMan) (computer program) Version 5.3. (Copenhagen: The Nordic Cochrane Centre, The Cochrane Collaboration, 2014) [21]. The relative risks (RR) with the $95 \%$ confidence intervals $(\mathrm{CI})$ were computed for each individual study, and RRs were combined using the Mantel-Haenszel random-effect model to take into account possible heterogeneity among studies rather than chance. A Forest plot was used for a graphical presentation of the results (reporting the effect estimates for the individual studies together with the overall measure of effect) and the selected studies were examined to assess the homogeneity/hetero- 


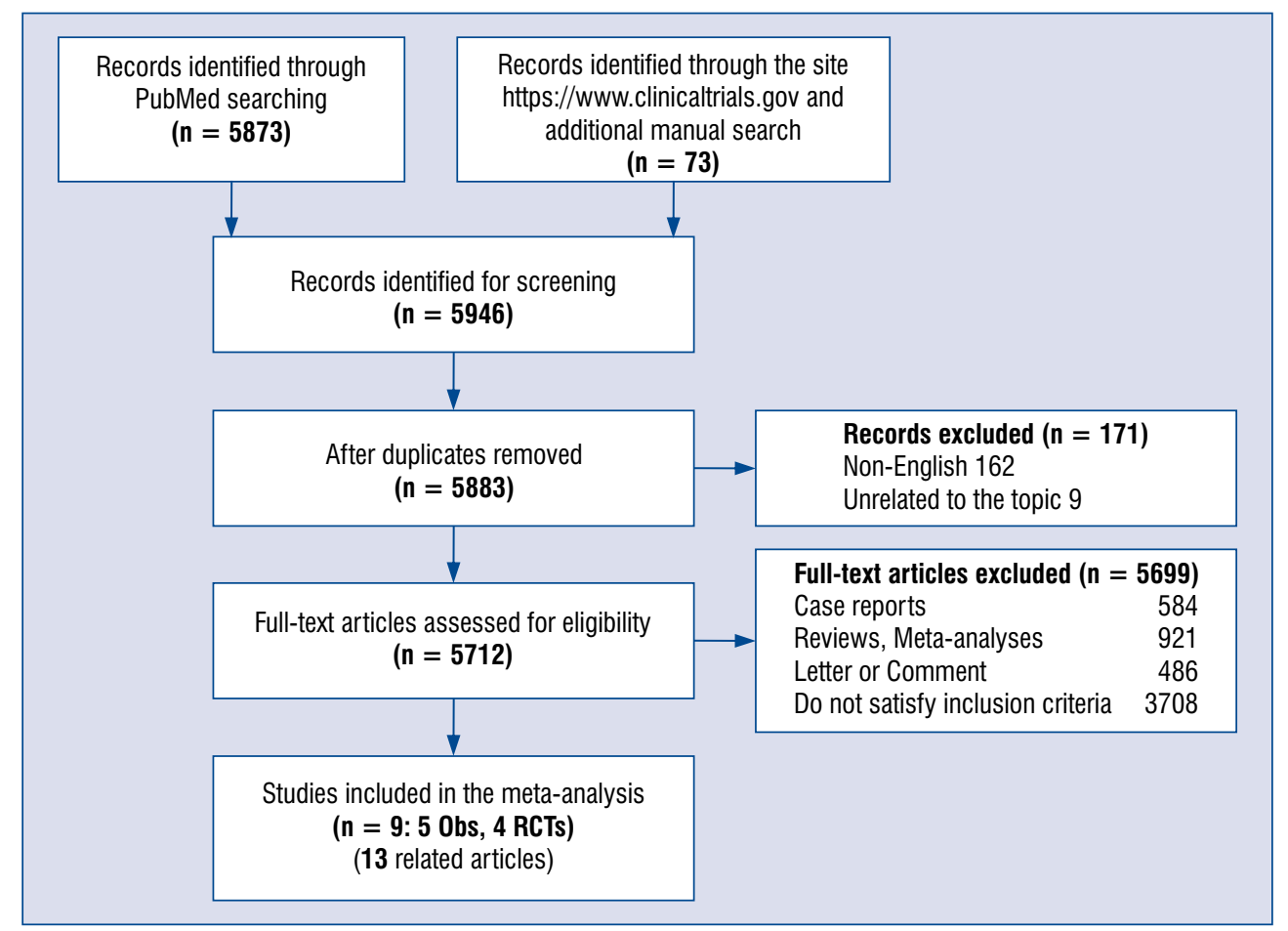

Figure 1. Flow-chart of the study selection process; Obs - observational studies; RCTs — randomized controlled trials.

geneity of the results by visually inspecting the overlap of the CIs of the risk estimates in the different studies and by computing the Cochran Q test and $\mathrm{I}^{2}$ statistics. The meta-analysis was performed taking into account RCTs and Obs subgroups, using the test for subgroup differences to evaluate the agreement/disagreement of the results between $\mathrm{RCTs}$ and Obs. In case of heterogeneity greater than moderate into each subgroup (i.e., $\mathrm{I}^{2}>60 \%$ ) [22] a funnel plot together with the $95 \%$ confidence limits around the summary treatment effect (i.e.: the expected distribution of studies in the absence of heterogeneity or of selection biases) [23] was drawn and a sensitivity analysis was performed by excluding the studies falling outside the $95 \% \mathrm{CI}$ at the visual inspection of the Funnel plot.

All statistical tests were two sided and alpha $(\alpha)$ error of $\leq 0.05$ was defined as statistically significant.

\section{Results}

After detailed review, 9 studies related to 4 RCTs $[4,5,8-11,13]$ and 5 Obs [14, 24-28] out of 5946 articles were selected (Fig. 1). The main characteristics of the selected studies are reported in Table 1.

\section{Primary endpoints}

30-day mortality was reported in 8 of the 9 selected studies and were assessed in 26,989 patients (2629 from 3 RCTs, 24,360 from 5 Obs) [5, 9, $11,14,24-27]$, occurred in $1.6 \%$ of TAVI compared to $2.7 \%$ of SAVR. Indeed, the study by Serruys et al. [13] on SURTAVI subgroup with STS $<3$ reports only 1 -year mortality. The overall analysis showed a non-significant risk reduction in TAVI compared to SAVR ( $R R=-36 \%, p=0.11)$; the analysis by subgroups showed in RCTs a significant risk reduction in favor of TAVI $(\mathrm{RR}=-56 \%, \mathrm{p}=0.04)$ while, in Obs the reduction of deaths in favor of TAVI was not significant $(\mathrm{RR}=-25 \%, \mathrm{p}=0.51$ ) (Fig. 2). Indeed, the RCTs showed homogeneous results $\left(\mathrm{I}^{2}=0 \%\right)$, whereas Obs were affected by high heterogeneity $\left(\mathrm{I}^{2}=67 \%\right)$ (Fig. 2A). The visual inspection of the Forest plot detected in the study by Schaefer et al. [25] indicated the potential source of bias: it was the only study with a RR significantly in favor of SAVR $(R R=3.56$, with a $95 \%$ CI ranging from 1.22 to 10.42; Fig. 2A). At the Funnel plot, the larger studies were plotted at the central top of the graph, demonstrating a convergence in the risk estimation with the increase of the sample size, whereas the smaller studies were scattered at the bottom of the graph. Again, the study of Schaefer 


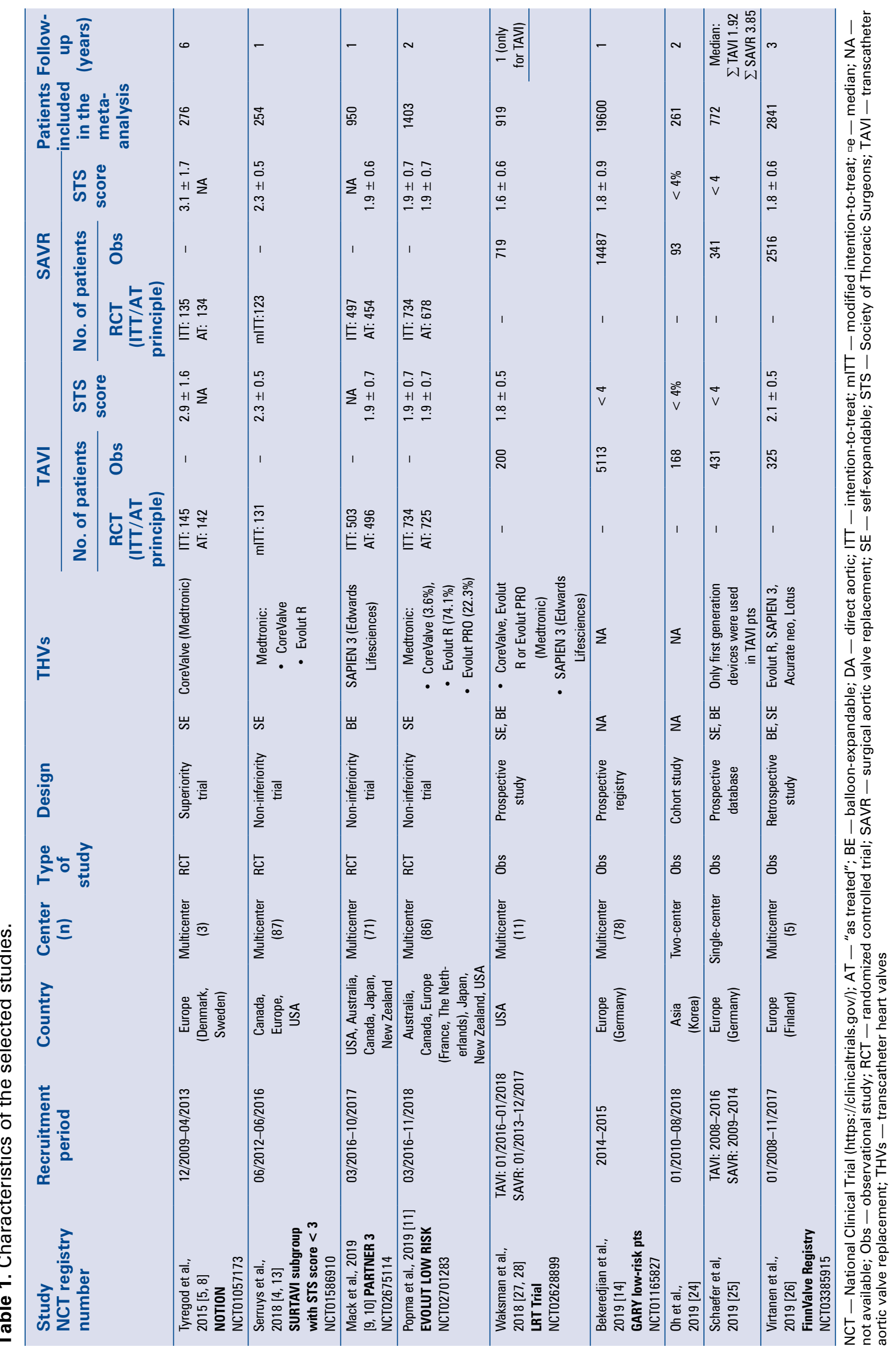




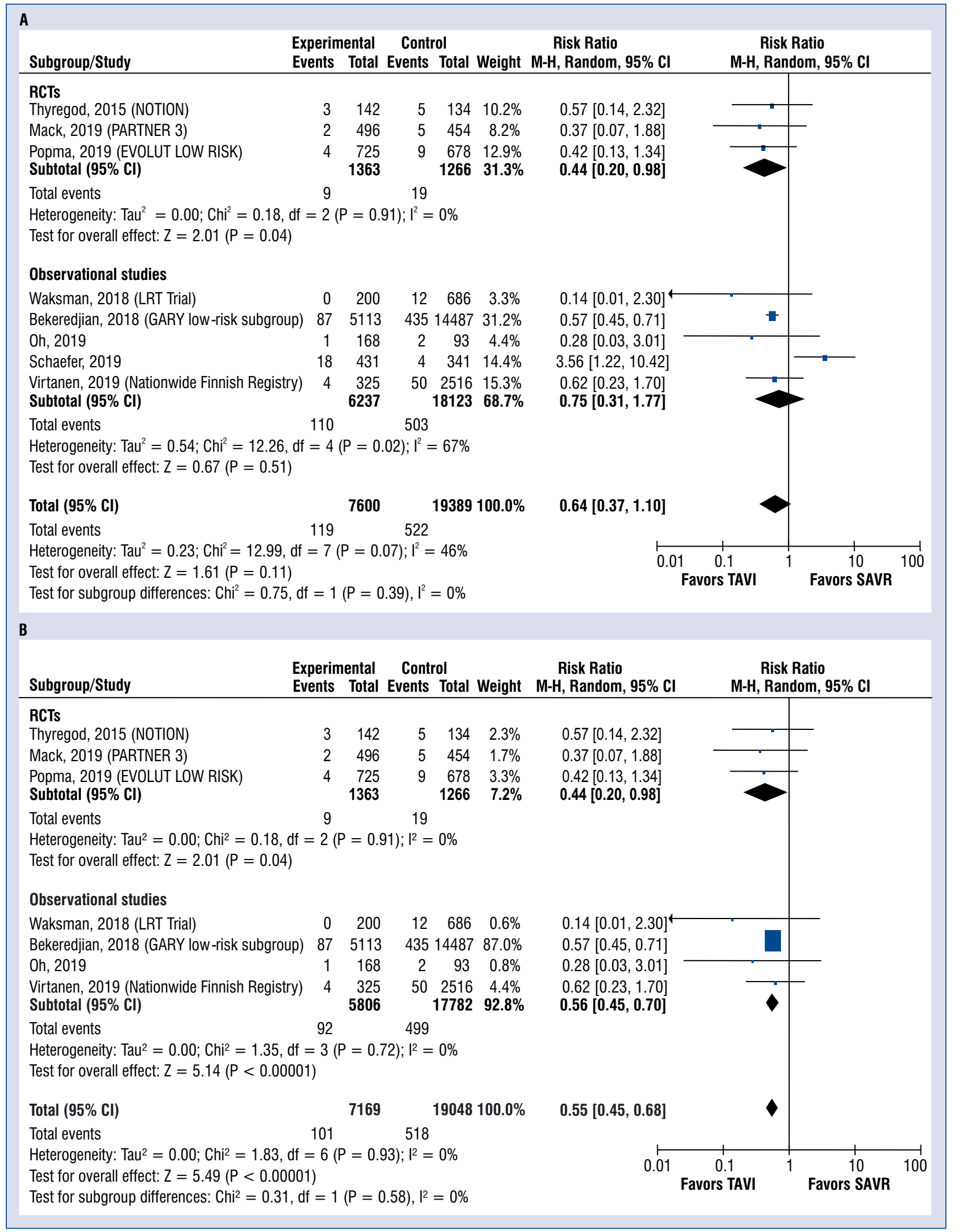

Figure 2. Forest plot of the primary end point: risk ratio of 30-day all-cause mortality between transcatheter aortic valve implantation (TAVI) and surgical aortic valve replacement (SAVR) in all studies (A) and after sensitivity analysis (B); $\mathrm{Cl}$ - confidence interval; $\mathrm{M}-\mathrm{H}$ - Mantel-Haenszel; RCTs — randomized controlled trials. 


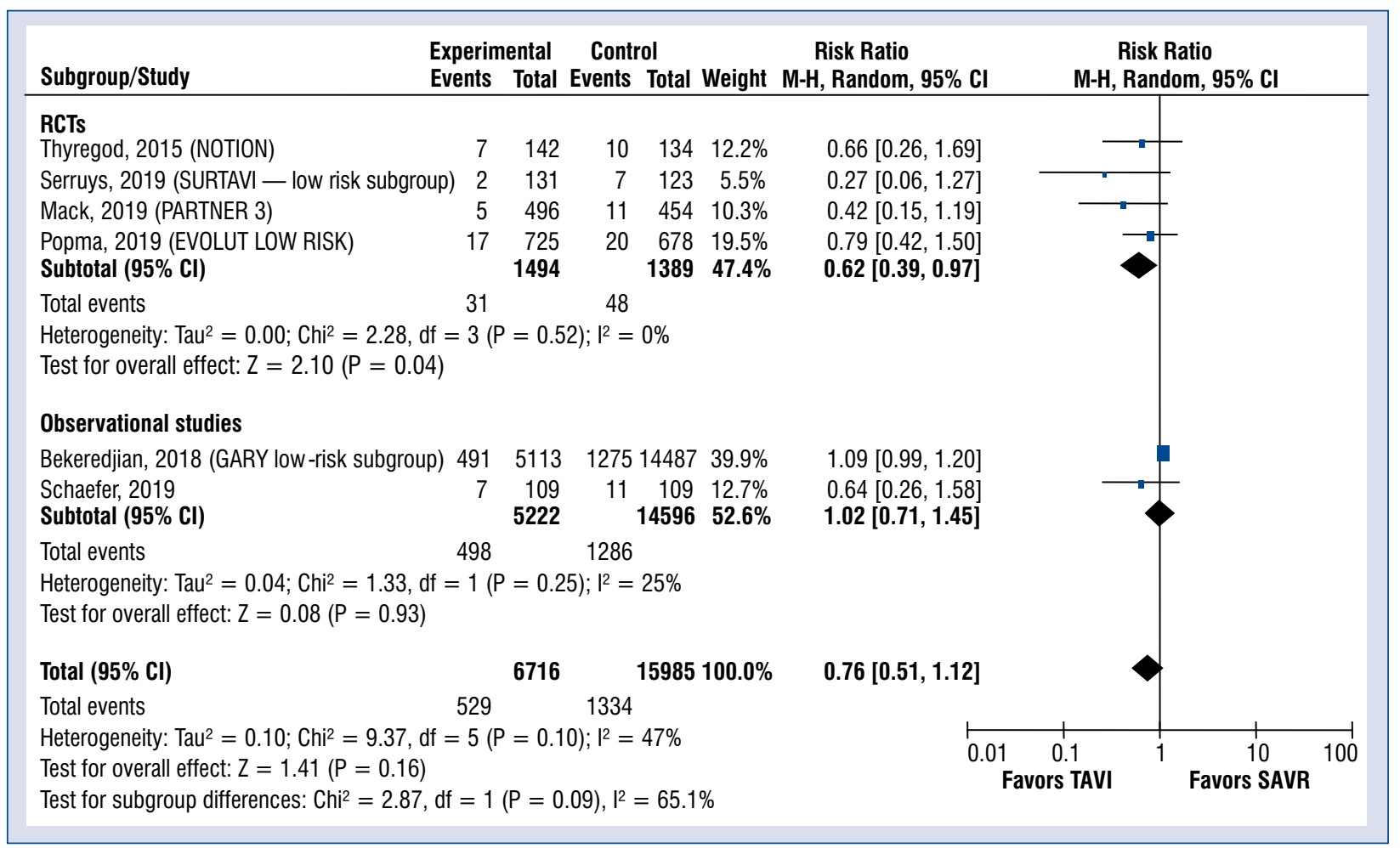

Figure 3. Forest plot of the primary end point: risk ratio of 1-year all-cause mortality between transcatheter aortic valve implantation (TAVI) and surgical aortic valve replacement (SAVR); $\mathrm{Cl}$ - confidence interval; $\mathrm{M}-\mathrm{H}$ - Mantel-Haenszel; RCTs - randomized controlled trials.

et al. [25] was the only one falling outside the 95\% CI. In the sensitivity analysis, by excluding the study by Schaefer et al. [25], the reduction in 30-day mortality in TAVI became significant also in the overall analysis $(\mathrm{RR}=-45 \%, \mathrm{p}<0.00001)$ and in Obs ( $R R=-44 \%, p<0.00001)$ in absence of heterogeneity $\left(\mathrm{I}^{2}=0 \%\right)$ (Fig. $\left.2 \mathrm{~B}\right)$. The test for subgroup difference showed agreement between RCTs and $\mathrm{Obs}\left(\mathrm{Chi}^{2}=0.31\right.$, df $=1, \mathrm{p}=0.58$, $\mathrm{I}^{2}=0 \%$; Fig. 2B).

One year mortality, was assessed in 22,701 patients (2883 from 4 RCTs, 19818 from 2 Obs) $[5,9,11,13,14,25]$. The overall analysis showed a non-significant risk reduction in TAVI compared to SAVR $(R R=-24 \%, p=0.16)$; the analysis by subgroups showed in RCTs a significant risk reduction in favor of TAVI $(\mathrm{RR}=-38 \%, \mathrm{p}=0.04)$ whereas in Obs non-significant risk increases in TAVI were observed $(R R=+2 \%, p=0.93$; Fig. 3 ). The results among the 4 RCTs were homogeneous $\left(\mathrm{I}^{2}=0 \%\right)$; a slight heterogeneity affected the $2 \mathrm{Obs}$ $\left(\mathrm{I}^{2}=25 \%\right)$. On the contrary, a high heterogeneity between RCTs and Obs was demonstrated in the test for subgroup differences $\left(\mathrm{Chi}^{2}=2.87, \mathrm{df}=1\right.$, $\mathrm{p}=0.09, \mathrm{I}^{2}=65.1 \%$; Fig. 3).

\section{Safety endpoints}

Permanent pacemaker. The overall analysis showed a significantly increased risk of new PM implantation for TAVI compared to SAVR $(p<0.0001)$. The risk was increased both in RCTs $(\mathrm{p}=0.007)$ and in Obs $(\mathrm{p}=0.02)$ for TAVI (Fig. 4A). However, the comparisons were affected by high heterogeneity both in RCTs $\left(\mathrm{I}^{2}=84 \%\right)$ and in Obs $\left(\mathrm{I}^{2}=88 \%\right.$ ) (Fig. 4A). At the Funnel plot 2 RCTs $[5,9]$ and 2 Obs $[25,27]$ fell outside the $95 \% \mathrm{CI}$ (Fig. 4B). By excluding these studies, the sensitivity analysis confirmed a significant increase of the risk for new PM $(\mathrm{p}<0.00001)$ with homogeneous results (Fig. 4A).

Major, life threatening or disabling bleeding. Definitions of bleeding for each included study are reported in Table 2 . VARC criteria were adopted by all the included studies with the only exclusion of Virtanen et al. [26]. This study, even though it was included in the initial analysis, was excluded in the sensitivity analysis because it was a source of heterogeneity (Fig. 4A).

The overall analysis showed a significant reduction of bleeding in TAVI compared to SAVR $(\mathrm{RR}=-65 \%, \mathrm{p}=0.008)$; the analysis by subgroups 


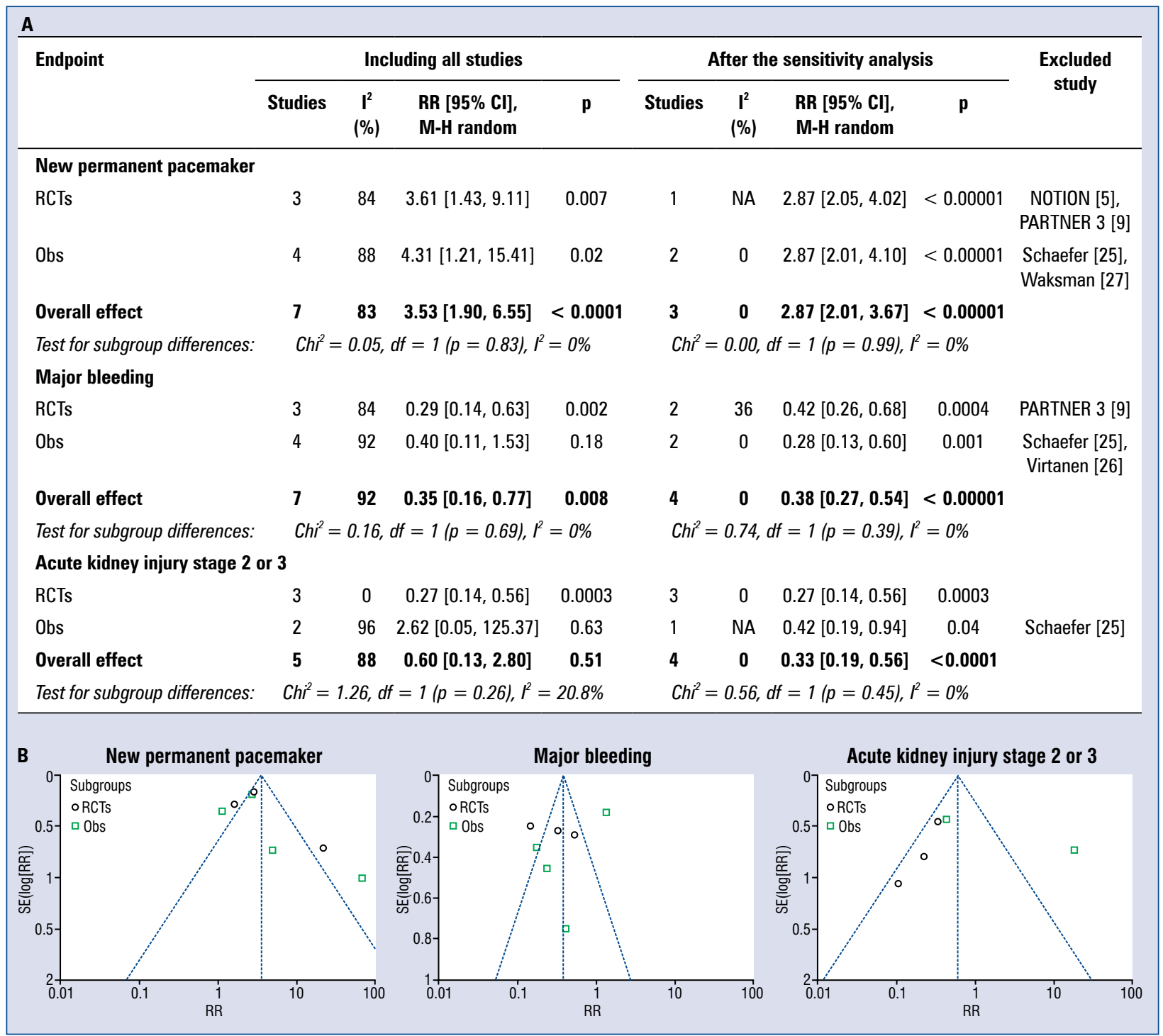

Figure 4. Thirty day safety endpoints: new permanent pacemaker implantation, major bleeding and acute kidney injury stage 2 or 3; A. Results of the comparisons between transcatheter aortic valve implantation and surgical aortic valve replacement before and after the sensitivity analysis; B. Funnel plots on the log of risk ratio (RR) of each safety end-point, plotted against the standard error (SE) of the log RR; dotted lines represent the risk estimate and its $95 \%$ confidence limits; $\mathrm{Cl}$ - confidence interval; $\mathrm{M}-\mathrm{H}$ - Mantel-Haenszel; NA — not applicable; Obs - observational studies; RCTs — randomized controlled trials.

showed in RCTs, was a significant risk reduction in favor of TAVI ( $R R=-71 \%, \mathrm{p}=0.002)$ whereas in Obs the reduction of bleeding in favor of TAVI was not significant $(\mathrm{RR}=-60 \%, \mathrm{p}=0.18$; Fig. $4 \mathrm{~A})$. Indeed, the overall heterogeneity was extremely high $\left(\mathrm{I}^{2}=92 \%\right)$ both in the RCTs $\left(\mathrm{I}^{2}=84 \%\right)$ and in Obs $\left(\mathrm{I}^{2}=92 \%\right)$ (Fig. $\left.4 \mathrm{~A}\right)$. After the sensitivity analysis, the comparisons were performed between more homogeneous populations (RCTs: $\mathrm{I}^{2}=36 \%$; Obs: $\mathrm{I}^{2}=0 \%$ ) and showed a significant reduction of major bleeding for TAVI both in RCTs $(\mathrm{p}=0.0004)$ and in Obs $(\mathrm{p}=0.001)$ (Fig. 4A). Indeed, Obs and $\mathrm{RCT}$ had the same trend in the test for subgroup differences (Fig. 4A).

Acute kidney injury stage 2 or 3 . The overall analysis showed a non-significant reduction of acute kidney injury in TAVI compared to SAVR $(\mathrm{RR}=-40 \%, \mathrm{p}=0.51$; Fig. $4 \mathrm{~A})$. In the analysis by subgroups, in RCTs ( $p=0.0003)$, but not in Obs $(\mathrm{p}=0.63)$, the risk of acute kidney injury was significantly reduced for TAVI (Fig. 4A). Indeed, RCTs were homogeneous $\left(\mathrm{I}^{2}=0 \%\right)$, but the Obs 
Table 2. Bleeding criteria definition.

\begin{tabular}{|c|c|c|}
\hline Included studies & Bleeding criteria & $\begin{array}{l}\text { Excluded at the } \\
\text { sensitivity analysis }\end{array}$ \\
\hline \multicolumn{3}{|c|}{ Randomized controlled trial } \\
\hline $\begin{array}{l}\text { Tyregod et al., } 2015 \\
\text { NOTION }\end{array}$ & VARC 2 & No \\
\hline $\begin{array}{l}\text { Mack et al., } 2019 \\
\text { PARTNER } 3\end{array}$ & VARC 2 & Yes \\
\hline $\begin{array}{l}\text { Popma et al., } 2019 \\
\text { EVOLUT LOW RISK }\end{array}$ & VARC 2 & No \\
\hline \multicolumn{3}{|l|}{ Observational study } \\
\hline $\begin{array}{l}\text { Waksman et al., } 2018 \\
\text { LRT Trial }\end{array}$ & $\begin{array}{l}\text { VARC } 2 \\
\text { (VARC } 2 \text { major bleeding for SAVR assumed if } \geq 3 \text { units } \\
\text { red blood cell transfusion given during procedure) } \\
\text { "Specific outcomes such as vascular complications and } \\
\text { major or life-threatening bleeding are not collected in } \\
\text { the STS database either and therefore could not be } \\
\text { compared. We therefore used the number of red blood } \\
\text { cell transfusions as a surrogate for bleeding." }\end{array}$ & No \\
\hline Oh et al., 2019 & VARC 2 & No \\
\hline Schaefer et al., 2019 & VARC 2 & Yes \\
\hline $\begin{array}{l}\text { Virtanen et al., } 2019 \\
\text { FinnValve Registry }\end{array}$ & $\begin{array}{c}\text { "In this study, the Valvular Academic Research Consor- } \\
\text { tium-2 definition of major and life-threatening bleeding } \\
\text { was not applied because, unlike patients undergoing } \\
\text { TAVR, a significant decrease of hemoglobin level is } \\
\text { observed in most patients undergoing SAVR, and this } \\
\text { does not always reflect a condition of major } \\
\text { perioperative blood loss." }\end{array}$ & Yes \\
\hline
\end{tabular}

SAVR - surgical aortic valve replacement; STS - Society of Thoracic Surgeons; TAVI — transcatheter aortic valve replacement; VARC 2 Valvular Academic Research Consortium-2

were not $\left(\mathrm{I}^{2}=96 \%\right)$, due to the study by Schaefer et al. [25] falling outside the $95 \% \mathrm{CI}$ at the Funnel plot (Fig. 4B). By excluding the study by Schaefer et al. [25], a significant reduction of acute kidney injury was observed for TAVI (Fig. 4A).

Stroke. The overall analysis showed a non-significant reduction of stroke in TAVI compared to SAVR ( $R R=-26 \%, p=0.21$; Fig. $5 A$ ). In the subgroups, the results of RCTs did not substantially differ from those of Obs: the risk of stroke was lower for TAVI, without reaching any statistically significant difference (Fig. 5A).

Paravalvular leak. A significant increase of moderate/severe paravalvular leak for TAVI in the overall analysis was observed $(\mathrm{p}<0.00001)$ both in RCTs $(p=0.0005)$ and in Obs $(p=0.001)$ (Fig. $5 \mathrm{~B})$. The results of the analysis of RCTs were in accordance with those of Obs (test for subgroup differences: $\mathrm{Chi}^{2}=0.01, \mathrm{df}=1, \mathrm{p}=0.92, \mathrm{I}^{2}=0 \%$ ) (Fig. 5B).

\section{Discussion}

The treatment of AS with TAVI in all patients in whom aortic valve surgery is indicated, irrespective of the surgical risk, is a useful goal to achieve because the interventional cardiology procedure is less invasive compared to cardiac surgery. Obviously, in order to extend the indications to TAVI in all patients with indications to SAVR, mostly in the low surgical risk, there must be conditions that allow it, and, in particular, the results of TAVI must be superimposable if not superior to those of surgical intervention $[29,30]$. A major boost in this direction was given by the results of PARTNER 3 and EVOLUT LOW RISK trials, performed on patients with severe AS at low risk of death with surgery, which demonstrated the benefits of TAVI over surgery $[9,11]$. Recently on the basis of RCTs [3-13] and registries [14, 24-28], TAVI was successfully reported in patients with moderate and 


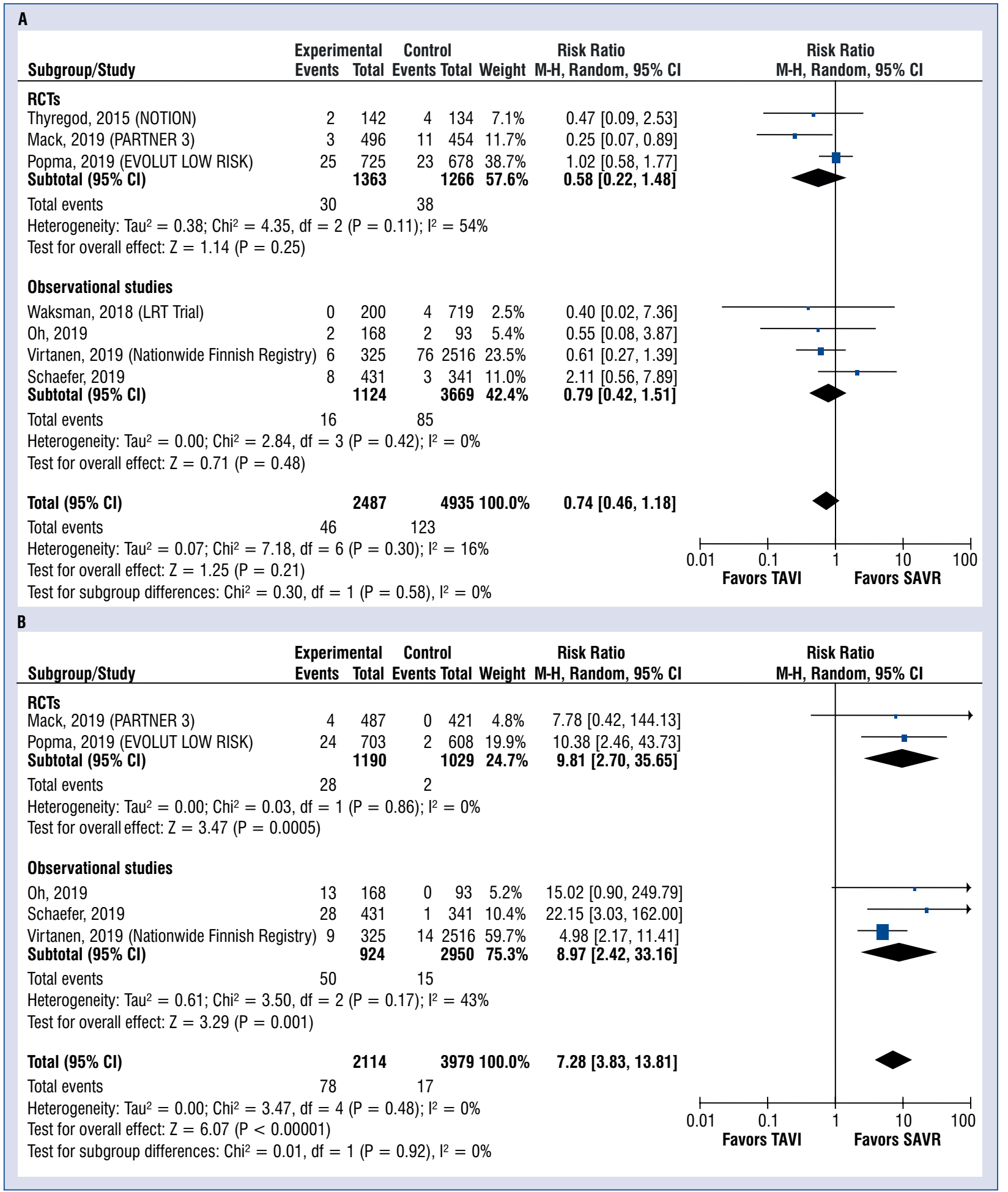

Figure 5. Forest plots of the 30-day safety endpoints: risk ratio of stroke (A) and paravalvular leak (B) between transcatheter aortic valve implantation (TAVI) and surgical aortic valve replacement (SAVR); $\mathrm{Cl}$ - confidence interval; $\mathrm{M}-\mathrm{H}$ - Martel-Heansel; RCTs — randomized controlled trials.

low surgical risk with comparable or even better results than SAVR. Due to the limited evidence coming from RCTs, the present meta-analysis also included available evidence coming from Obs with the aim of increasing the power of analysis. However, the meta-analysis was performed by the two 
subgroups in order to take into account separately the results coming from the two types of studies. The test for difference between RCTs and Obs was also computed to evaluate their agreement/ /disagreement. Indeed, as stated by Briere et al. [31], "the inclusion of real-world evidence in meta-analyses may facilitate the confirmation of conclusions drawn from randomized controlled trials and, thus, reassure decision-makers that findings can be extrapolated to real-world populations." [31]. In the comparisons evaluating 30-day mortality, after the exclusion of the study by Schaefer et al. [25] according to the sensitivity analysis, the results of the meta-analysis with both RCTs and Obs were homogeneous $\left(\mathrm{I}^{2}=0 \%\right)$ and superimposable and highlighted a significant $45 \%$ reduction in mortality in the patients undergoing TAVI (Fig. 2B). Indeed, the study by Schaefer et al. [25] was a source of heterogeneity not only in 30-day mortality but also in the analysis of many safety endpoints. As affirmed by Schaefer et al. [25]: "An important limitation of this study is that only first-generation devices were used in TAVI patients" and despite: "Baseline, procedural, and follow-up data were prospectively collected from dedicated databases" data were "retrospectively analyzed", having all the limitations of a retrospective study design [25].

In the present meta-analysis, at 1 year follow up, only the analysis of RCTs showed a significantly lower mortality in TAVI compared SAVR $(p=0.04)$, in disagreement with the results of the overall analysis, which nevertheless was affected by high heterogeneity in the test for subgroup differences $\left(\mathrm{I}^{2}=65.1 \%\right)$ (Fig. 3).

As for the safety endpoints, the analysis did not demonstrate a different incidence of stroke between TAVI and SAVR (Fig. 5A). Furthermore, in TAVI a significantly increased risk of paravalvular leak (Fig. 5B) and new PM implantation (Fig. 4A) was observed (Fig. 5B). However, the analysis on new PM implantation was affected by high heterogeneity both in the overall effect $\left(\mathrm{I}^{2}=83 \%\right)$ and into each subgroup (RCTs, $\mathrm{I}^{2}=84 \%$; Obs, $\mathrm{I}^{2}=88 \%$ ); Fig. 5A). As reported in the literature, this heterogeneity could be attributable to the inclusion of different types of prostheses in the analysis (Table 1) [32,33].

\section{Limitations of the study}

The analysis of Obs could overestimate the effect of the treatment, due to the lack of randomization [34, 35]. However, the results of Obs were in agreement with RCTs for most comparisons, except when including the study of Schaefer et al. [25]. The reason was probably related (i) to the procedures performed in different intervals of time and (ii) to exclusive implantation of first-generation devices in TAVI (Table 1).

\section{Conclusions}

On the basis of the results of this meta-analysis TAVI is not superimposable to SAVR in patients with severe AS at low surgical risk. Some differences have to be highlighted. In particular, if 30-day and 1-year mortality, major/life threatening or disabling bleeding and acute kidney injury stage 2 or 3 were significantly lower for TAVI, the need of new PM implantation and perivalvular leak were significantly lower in SAVR. Indeed, these last two events do not always have an early prognostic impact, but their long-term implications have not yet been established.

Consequently, we suggest the need of more trials to evaluate the effectiveness of TAVI as routine therapeutic procedure in the treatment of patients with low surgical risk severe AS.

\section{Conflict of interest: None declared}

\section{References}

1. Nishimura RA, Otto CM, Bonow RO, et al. 2017 AHA/ACC Focused Update of the 2014 AHA/ACC Guideline for the Management of Patients With Valvular Heart Disease: A Report of the American College of Cardiology/American Heart Association Task Force on Clinical Practice Guidelines. Circulation. 2017; 135(25): e1159-e1195, doi: 10.1161/CIR.0000000000000503, indexed in Pubmed: 28298458.

2. Baumgartner H, Falk V, Bax JJ, et al. 2017 ESC/EACTS Guidelines for the management of valvular heart disease. Eur Heart J. 2017; 38(36): 2739-2791, doi: 10.1093/eurheartj/ehx391, indexed in Pubmed: 28886619.

3. Leon M, Smith C, Mack M, et al. Transcatheter or Surgical Aortic-Valve Replacement in Intermediate-Risk Patients. N Engl J Med. 2016; 374(17): 1609-1620, doi: 10.1056/nejmoa1514616.

4. Reardon M, Van Mieghem N, Popma J, et al. Surgical or transcatheter aortic-valve replacement in intermediate-risk patients. N Engl J Med. 2017; 376(14): 1321-1331, doi: 10.1056/ nejmoa1700456.

5. Thyregod HG, Steinbrüchel DA, Ihlemann N, et al. Transcatheter versus surgical aortic valve replacement in patients with severe aortic valve stenosis: 1 -year results from the all-comers NOTION randomized clinical trial. J Am Coll Cardiol. 2015; 65(20): 2184-2194, doi: 10.1016/j.jacc.2015.03.014, indexed in Pubmed: 25787196.

6. Søndergaard L, Steinbrüchel DA, Ihlemann N, et al. Two-Year outcomes in patients with severe aortic valve stenosis randomized to transcatheter versus surgical aortic valve replacement: the allcomers nordic aortic valve intervention randomized clinical trial. Circ Cardiovasc Interv. 2016; 9(6), doi: 10.1161/CIRCINTERVENTIONS.115.003665, indexed in Pubmed: 27296202.

7. Thyregod HG, Ihlemann N, Jørgensen TH, et al. Five-Year clini$\mathrm{cal}$ and echocardiographic outcomes from the nordic aortic valve intervention (NOTION) randomized clinical trial in lower surgical risk patients. Circulation. 2019 [Epub ahead of print], doi: 10.1161/ CIRCULATIONAHA.118.036606, indexed in Pubmed: 30704298. 
8. Søndergaard L, Ihlemann N, Capodanno D, et al. Durability of transcatheter and surgical bioprosthetic aortic valves in patients at lower surgical risk. J Am Coll Cardiol. 2019; 73(5): 546-553, doi: 10.1016/j.jacc.2018.10.083, indexed in Pubmed: 30732707.

9. Pibarot P, Salaun E, Dahou A, et al. Transcatheter aortic-valve replacement with a balloon-expandable valve in low-risk patients. N Engl J Med. 2019; 380(18): 1695-1705, doi: 10.1056/ NEJMoa1814052, indexed in Pubmed: 30883058.

10. Pibarot P, Salaun E, Dahou A, et al. Echocardiographic results of transcatheter versus surgical aortic valve replacement in lowrisk patients: the PARTNER 3 trial. Circulation. 2020; 141(19): 1527-1537, doi: 10.1161/CIRCULATIONAHA.119.044574, indexed in Pubmed: 32272848.

11. Popma JJ, Deeb GM, Yakubov SJ, et al. Transcatheter aortic-valve replacement with a self-expanding valve in low-risk patients. N Engl J Med. 2019; 380(18): 1706-1715, doi: 10.1056/NEJMoa1816885, indexed in Pubmed: 30883053.

12. Baron SJ, Magnuson EA, Lu M, et al. Health status after transcatheter versus surgical aortic valve replacement in low-risk patients with aortic stenosis. J Am Coll Cardiol. 2019; 74(23): 2833-2842, doi: 10.1016/j.jacc.2019.09.007, indexed in Pubmed: 31577923.

13. Serruys PW, Modolo R, Reardon M, et al. One-year outcomes of patients with severe aortic stenosis and an STS PROM of less than three percent in the SURTAVI trial. EuroIntervention. 2018; 14(8): 877-883, doi: 10.4244/EIJ-D-18-00460, indexed in Pubmed: 29992904.

14. Bekeredjian R, Szabo G, Balaban Ü, et al. Patients at low surgical risk as defined by the Society of Thoracic Surgeons Score undergoing isolated interventional or surgical aortic valve implantation: in-hospital data and 1-year results from the German Aortic Valve Registry (GARY). Eur Heart J. 2019; 40(17): 1323-1330, doi: 10.1093/eurheartj/ehy699, indexed in Pubmed: 30445543.

15. Prendergast BD, Redwood SR. Transcatheter aortic valve replacement. Circulation. 2019; 139(24): 2724-2727, doi: 10.1161/ CIRCULATIONAHA.119.040016, indexed in Pubmed: 31180746.

16. Prendergast BD, Baumgartner H, Delgado V, et al. Transcatheter heart valve interventions: where are we? Where are we going? Eur Heart J. 2019; 40(5): 422-440, doi: 10.1093/eurheartj/ ehy668, indexed in Pubmed: 30608523.

17. O'Brien SM, Shahian DM, Filardo G, et al. The Society of Thoracic Surgeons 2008 cardiac surgery risk models: Part 2 - isolated valve surgery. Ann Thorac Surg. 2009; 88(1 Suppl): S23-S42, doi: 10.1016/j.athoracsur.2009.05.056, indexed in Pubmed: 19559823.

18. Nashef SAM, Roques F, Sharples LD, et al. Risk factors and outcome in European cardiac surgery: analysis of the EuroSCORE multinational database of 19030 patients. Eur J Cardiothorac Surg. 1999; 15(6): 816-822, doi: 10.1016/s1010-7940(99)00106-2, indexed in Pubmed: 10431864.

19. Roques F, Michel P, Goldstone AR, et al. The logistic EuroSCORE. Eur Heart J. 2003; 24(9): 881-882, doi: 10.1016/s0195668x(02)00799-6, indexed in Pubmed: 12727160.

20. Kappetein A, Head S, Généreux P, et al. Updated standardized endpoint definitions for transcatheter aortic valve implantation: the Valve Academic Research Consortium-2 consensus document $\uparrow$. Eur Heart J. 2012; 33(19): 2403-2418, doi: 10.1093/eurheartj/ehs255.

21. Review Manager (RevMan) [Computer program]. Version 5.3. Copenhagen: The Nordic Cochrane Centre, the Cochrane Collaboration, 2014

22. Higgins JPT, Thomas J, Chandler J, Cumpston M, Li T, Page MJ, Welch VA (editors). Cochrane Handbook for Systematic Reviews of Interventions version 6.0 (updated July 2019). Cochrane, 2019. www.training.cochrane.org/handbook.

23. Sterne JAC, Sutton AJ, Ioannidis JPA, et al. Recommendations for examining and interpreting funnel plot asymmetry in metaanalyses of randomised controlled trials. BMJ. 2011; 343: d4002, doi: 10.1136/bmj.d4002, indexed in Pubmed: 21784880.

24. Oh JK, Park SJ, Kim HoJ, et al. Transcatheter versus surgical aortic valve replacement in low-risk, elderly patients with severe aortic stenosis. J Am Coll Cardiol. 2019; 74(11): 1514-1515, doi: 10.1016/j.jacc.2019.07.028, indexed in Pubmed: 31514956.

25. Schaefer A, Schofer N, Goßling A, et al. Transcatheter aortic valve implantation versus surgical aortic valve replacement in low-risk patients: a propensity score-matched analysis. Eur J Cardiothorac Surg. 2019; 56(6): 1131-1139, doi: 10.1093/ejcts/ ezz245, indexed in Pubmed: 31566209.

26. Virtanen MPO, Eskola M, Jalava MP, et al. Comparison of outcomes after transcatheter aortic valve replacement vs surgical aortic valve replacement among patients with aortic stenosis at low operative risk. JAMA Netw Open. 2019; 2(6): e195742, doi: 10.1001/jamanetworkopen.2019.5742, indexed in Pubmed: 31199448.

27. Waksman R, Rogers T, Torguson R, et al. Transcatheter aortic valve replacement in low-risk patients with symptomatic severe aortic stenosis. J Am Coll Cardiol. 2018; 72(18): 2095-2105, doi: 10.1016/j.jacc.2018.08.1033.

28. Waksman R, Corso PJ, Torguson R, et al. TAVR in low-risk patients: 1-year results from the LRT trial. JACC Cardiovasc Interv. 2019; 12(10): 901-907, doi: 10.1016/j.jcin.2019.03.002, indexed in Pubmed: 30860059.

29. Bleakley C, Monaghan MJ. The pivotal role of imaging in TAVR procedures. Curr Cardiol Rep. 2018; 20(2): 9, doi: 10.1007/ s11886-018-0949-z, indexed in Pubmed: 29435741.

30. Blanke P, Weir-McCall JR, Achenbach S, et al. Computed Tomography Imaging in the Context of Transcatheter Aortic Valve Implantation (TAVI)/Transcatheter Aortic Valve Replacement (TAVR): An Expert Consensus Document of the Society of Cardiovascular Computed Tomography. JACC Cardiovasc Imaging. 2019; 12(1): 1-24, doi: 10.1016/j.jcmg.2018.12.003, indexed in Pubmed: 30621986.

31. Briere JB, Bowrin K, Taieb V, et al. Meta-analyses using real-world data to generate clinical and epidemiological evidence: a systematic literature review of existing recommendations. Curr Med Res Opin. 2018; 34(12): 2125-2130, doi: 10.1080/03007995.2018.1524751, indexed in Pubmed: 30217138.

32. Acconcia MC, Caretta Q, Monzo L, et al. Effectiveness of the new generation transcatheter aortic valve in the real life studies. Review and meta-analysis. Eur Rev Med Pharmacol Sci. 2019; 23(18): 8018-8027, doi: 10.26355/eurrev_201909_19018, indexed in Pubmed: 31599427.

33. Vlastra W, Chandrasekhar J, Muñoz-Garcia AJ, et al. Comparison of balloon-expandable vs. self-expandable valves in patients undergoing transfemoral transcatheter aortic valve implantation: from the CENTER-collaboration. Eur Heart J. 2019; 40(5): 456-465, doi: 10.1093/eurheartj/ehy805, indexed in Pubmed: 30590565.

34. Saturni S, Bellini F, Braido F, et al. Randomized Controlled Trials and real life studies. Approaches and methodologies: a clinical point of view. Pulm Pharmacol Ther. 2014; 27(2): 129-138, doi: 10.1016/j.pupt.2014.01.005, indexed in Pubmed: 24468677.

35. Sørensen HT, Lash TL, Rothman KJ. Beyond randomized controlled trials: a critical comparison of trials with nonrandomized studies. Hepatology. 2006; 44(5): 1075-1082, doi: 10.1002/ hep.21404, indexed in Pubmed: 17058242. 